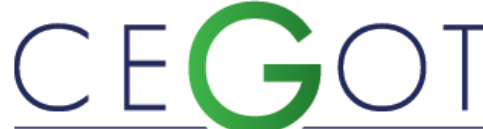

Centro de Estudos de Geografia e Ordenamento do Território
Centro de História da Arte e Investigação Artística (CHAIA) Universidade de Évora

Palácio do Vimioso, Largo Marquês de Marialva 8, 7002-554, Évora, Portugal amoya@uevora.pt

\title{
Sustentabilidade sociocultural na paisagem urbana histórica e multicultural no Bairro da Mouraria, Lisboa
}

Sociocultural sustainability in the multicultural and historical urban landscape in Mouraria neighbourhood, Lisbon

Referência: Moya, Ana (2019). Sustentabilidade sociocultural na paisagem urbana histórica e multicultural no Bairro da Mouraria, Lisboa. Revista de Geografia e Ordenamento do Território (GOT), n. 17 (junho). Centro de Estudos de Geografia e Ordenamento do Território, p. 179-199, dx.doi.org/10.17127/got/2019.17.008

\section{RESUMO}

A gentrificação causada pelo turismo de cidades, juntamente com a diversidade cultural dos novos residentes imigrados, têm efeitos sobre a transformação da identidade da paisagem urbana histórica da Mouraria, em Lisboa. Os processos de evolução da identidade patrimonial dependem tanto das políticas de reabilitação urbana como dos atores e residentes ativos no desenvolvimento socioeconómico e cultural do bairro. 0 mapeamento das relações espácio-temporais dos atores da Mouraria permite-nos entender os padrões de sustentabilidade sociocultural existentes e entender os potenciais de desenvolvimento, conservação e regeneração da identidade da sua paisagem patrimonial. A estrutura associativa tem um papel fulcral na sustentabilidade sociocultural do bairro, tanto na preservação dos legados culturais como na construção de novas dinâmicas económicas, sociais e interculturais baseadas no desenvolvimento e participação das comunidades na construção da identidade patrimonial da Mouraria.

Palavras-chave: Paisagem urbana histórica, identidade patrimonial, sustentabilidade sociocultural, multiculturalidade, transformação espácio-temporal.

\section{ABSTRACT}

Gentrification caused by city tourism, together with the cultural diversity of the new immigrant residents have effects on the transformation of the identity of the historic urban landscape of Mouraria, in Lisbon. Processes of evolution of the heritage identity depend as much upon urban rehabilitation policies as in the actors and residents active in the socioeconomic and cultural development of the neighbourhood. Mapping the actor's space-time relations in the urban space of Mouraria, allow us to recognise the sociocultural sustainable patterns present in the neighbourhood, and to understand the potentials of development, identity preservation and regeneration of its landscape heritage. The associative structure 
plays a central role in the socio-cultural sustainability of the neighbourhood, both in the preservation of cultural legacies and in the construction of new social, intercultural and economic dynamics based on the development and participation of the communities in the construction of Mouraria's patrimonial identity.

Keywords: Historic urban landscape, heritage identity, socio-cultural sustainability, multiculturality, spatio-temporal transformations

\section{Introdução: a autenticidade patrimonial da paisagem urbana}

O peso dado à identidade e aos valores patrimoniais da paisagem urbana histórica da Mouraria deve ser proporcional à importância dos seus atributos materiais e imateriais e ao impacto da mudança sobre eles (ICOMOS, 4:2011). A avaliação qualitativa destes recursos da paisagem urbana está inevitavelmente implicada no seu processo avaliativo.

Na Recomendação sobre a Paisagem Urbana Histórica da UNESCO (2011) aconselha-se incluir na noção de paisagem urbana histórica as tradições e perceções das comunidades locais e envolver os valores das suas comunidades nacionais e internacionais (população imigrada e multicultural), dos jovens e dos coletivos insuficientemente representados. As práticas e valores sociais e culturais e as dimensões intangíveis do património relativas à diversidade e criatividade cultural das comunidades são atributos importantes no desenvolvimento e preservação patrimonial da paisagem urbana.

Para poder manter viva a autenticidade patrimonial do bairro da Mouraria, requer-se que o mesmo seja autêntico e esteja vivo, seja dinâmico e permita a qualidade de vida dos seus moradores. É necessária a sustentabilidade sociocultural, baseada num equilíbrio entre o desenvolvimento económico e cultural e a continuidade dos legados identitários. Sem a inclusão social e a comunicação e participação ativa dos seus residentes, não é possível uma evolução identitária sustentável (Turner, 2015).

O património da paisagem urbana da Mouraria é um bem social, cultural e económico. Forma parte dos valores identitários compartilhados da sua comunidade, dos legados históricos da cidade e é determinante de uma qualidade meio ambiental que é dinamizadora da economia, desde o ponto de vista do investimento imobiliário, turístico, e da indústria cultural. A conservação do património da paisagem urbana por parte das 
políticas públicas considera estes factos. Por exemplo, o Programa de Ação da Mouraria (PA, 2009), que teve início no ano 2011 até 2013, implicou um conjunto de operações de valorização patrimonial tanto material como imaterial do bairro. Houve melhorias no sistema de espaços públicos e na requalificação da imagem urbana, e no apoio a estruturas sociais e a iniciativas culturais com o intuito de reforçar a identidade urbana e os potenciais multiculturais da comunidade. Como afirma a Recomendação sobre a Paisagem Urbana Histórica da UNESCO, os valores patrimoniais da paisagem urbana já não se encontram unicamente nos monumentos e conjuntos arquitetónicos, mas também no reconhecimento mais amplo dos processos sociais, culturais e económicos que estabelecem um desenvolvimento sustentável e que permitem preservar e acentuar uma específica qualidade urbana ambiental que se fundamenta numa complexa inter-relação entre o espaço físico geomorfológico e as práticas sociais na sua dimensão intangível relacionadas com a diversidade cultural e a criatividade.

Os lugares mudam e as suas comunidades também evoluem, transformam-se e adaptam-se aos novos tempos, com elas também mudam as significações e as perceções culturais da paisagem e os seus valores patrimoniais. Como identificar as variáveis de mudança, continuidade e resiliência da identidade patrimonial da paisagem urbana dentro de processos de mobilidade e multiculturalidade? Os efeitos do neoliberalismo e a globalização têm transformado a população da Mouraria numa comunidade "super-diversa" imigrada de 51 nacionalidades diferentes (Fonseca, McGarrigle, 2012), junto com o aumento de um turismo dinâmico e imersivo ligado à economia colaborativa das novas gerações digitais. Este facto gera padrões de deslocação, isolamento e sentido de não pertença ao lugar ou de perda do lugar, com consequências negativas para a continuidade e construção identitária da paisagem urbana tanto para os novos vindos como para a população cada vez mais envelhecida dos "filhos do bairro" (Menezes, 2004). A "superdiversidade" migratória dos novos vindos implica uma amplitude e variabilidade nas suas condições de integração no bairro que afectam as futuras dinâmicas de interação multicultural. A preservação da autenticidade da vida urbana na Mouraria depende do equilíbrio entre a continuidade das tradições bairristas e a incorporação de novas agendas e atividades sociais e culturais adaptadas às tradições dos novos vindos dentro das estruturas sociais já existentes como da criação de novos grupos associativos abertos ao apoio, colaboração e visibilidade 
multicultural. Os valores patrimoniais existentes tanto materiais como imateriais da paisagem urbana têm um papel fundamental na resiliência social e cultural do bairro. 0 património contribui para a coesão social, o desenvolvimento sustentável e o bem-estar emocional e psicológico da sua população, especialmente em situações de mudança, ameaça de perda do lugar e destruição do ecossistema urbano (Jigyasu, [et.al], 2013). Com as mudanças e a rápida transformação da paisagem urbana nos centros históricos, como no caso da Mouraria, também muda o ecossistema emocional dos seus habitantes sendo necessária a redefinição dos universos mentais individuais e coletivos que os prendem ao lugar, na procura de novos imaginários que proporcionem apego, familiaridade e identidade tanto para os "filhos do bairro" como para os novos vindos. As comunidades resilientes são aquelas que reconhecem os legados patrimoniais da sua paisagem urbana como condutores da sua própria reação e salvaguarda emocional às mudanças, mas também são aquelas que alargam a identidade patrimonial das suas comunidades para abranger novas semânticas culturais que permitem a justaposição dos diferentes discursos multiétnicos. É por essa razão que as associações locais no bairro têm um papel fulcral nos padrões de sustentabilidade sociocultural do bairro que implica a inclusão social e a comunicação e participação ativa de todos os seus residentes.

\section{A evolução da identidade patrimonial da paisagem urbana}

O património tangível e intangível da paisagem urbana da Mouraria, em Lisboa, que chega até os nossos dias, tem estado submetido a processos históricos de construção e transformação. As alterações na paisagem urbana ao longo da história implicam processos de mudança social, cultural e económica no bairro, dando lugar a importantes ausências, mudanças e descontinuidades dos seus valores e atributos identitários. No entanto são as suas permanências identitárias que têm chegado aos nossos dias, aquelas que têm contribuído para manter a autenticidade de uma específica qualidade urbana ambiental e histórica. 


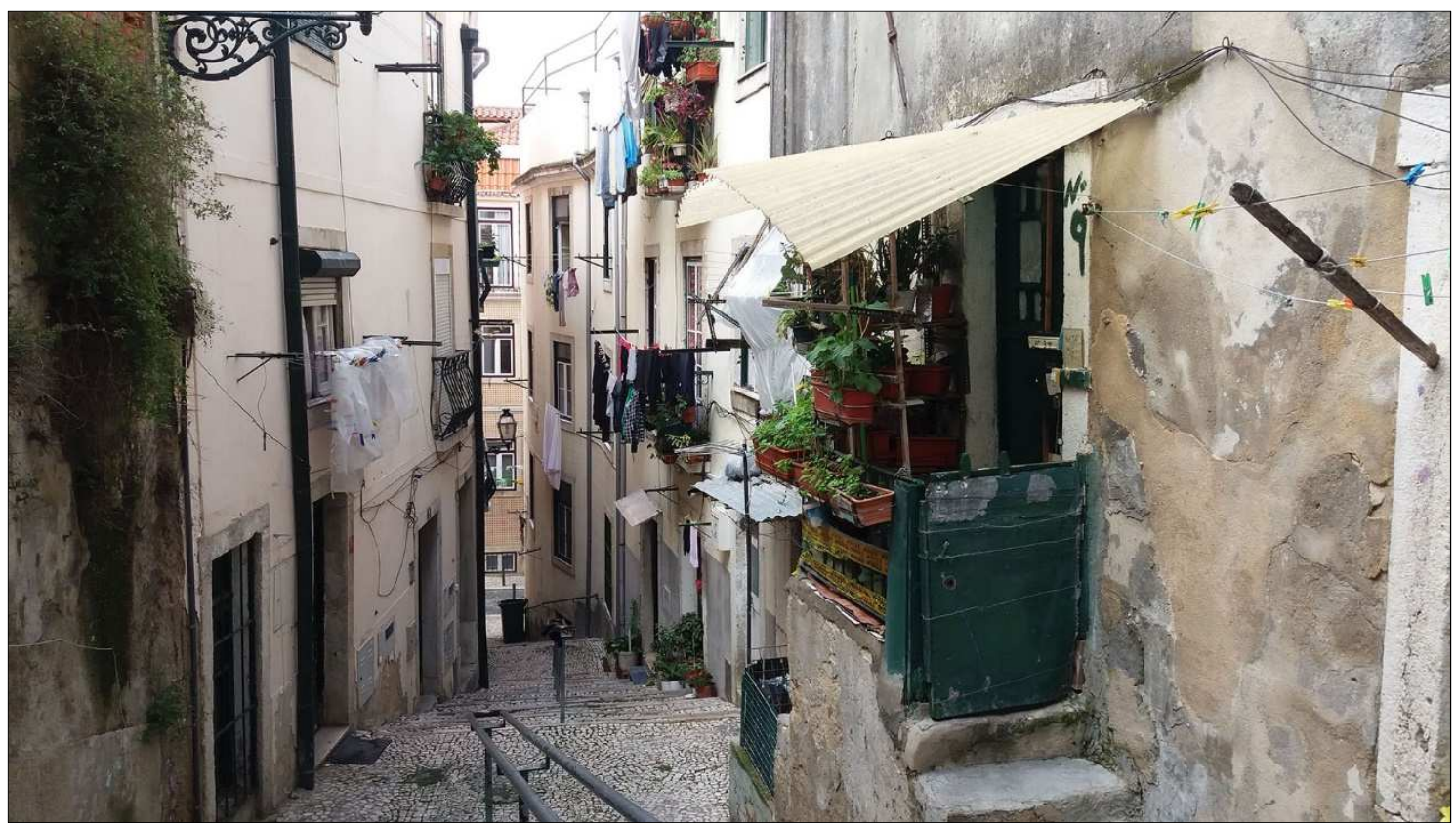

Figura $1-0$ atributo patrimonial da estrutura física irregular da Mouraria com elementos fundamentais do urbanismo islâmico. Beco do Castelo, 2016. Fonte: Ana Moya.

Existem uma série de elementos da morfologia física e do tecido construído do bairro que formam parte das permanências tangíveis mais relevantes da sua paisagem urbana. $\mathrm{O}$ bairro foi pouco afetado pelo terramoto de 1755 , e só pontualmente foi objeto de reconstrução pombalina. Este facto permitiu a conservação da sua estrutura espacial com elementos fundamentais do urbanismo islâmico. Os seus atributos patrimoniais encontram-se na sua estrutura física irregular, de ruas estreitas e sinuosas, com múltiplos recantos, becos e escadarias que se adaptam à topografia, e detém uma determinada compacidade em todo o seu tecido construído (Figura 1). A catalogação patrimonial do Plano de Urbanização do Núcleo Histórico da Mouraria (1997) ${ }^{1}$ destaca-se igrejas, conventos e palácios que tiveram um papel preponderante na estrutura público-religiosa da cidade, entre eles a Ermida de São Sebastião (Século XVI), mais tarde designada por Capela de Nossa Senhora da Saúde (1662), que sobreviveu miraculosamente às demolições da Baixa da Mouraria nos anos 1950, com a devoção popular à procissão da sua virgem dentro dos rituais religiosos mais importantes da Mouraria e de Lisboa. Pior sorte teve a Igreja N. Sra. do Socorro (1646) construída como sede da Freguesia do Socorro, que foi destruída durante o terramoto de 1755, e reconstruída em 1816, referente identitário da Mouraria e demolida demolida

\footnotetext{
${ }^{1}$ Câmara Municipal de Lisboa- Plano de Urbanização do Núcleo Histórico da Mouraria. Volume 2. Elementos cartográficos e Volume 4. Anexos. Caracterização urbana. Parte escrita. Lisboa: CML, 1997.
} 
definitivamente na estratégia de higienização urbana na década de 1950. A Igreja de São Cristóvão (1670) tem um papel fulcral na vida religiosa da comunidade cristã da Mouraria. No ano 2016 esteve a decorrer o projeto "Arte por São Cristovão", vencedor do Orçamento Participativo de Lisboa, para captar apoios para a renovação seguindo um Plano de Conservação e Revitalização da Igreja.

$\mathrm{Na}$ atualidade, o bairro encontra-se num processo de revitalização e renovação urbana. Passou de bairro estigmatizado até ao ano 2010, com a sua identidade marcada pela degradação do edificado, o envelhecimento da população, a pobreza, o abandono, o tráfico de drogas e a prostituição, a um bairro que na atualidade está na moda, sujeito aos processos de gentrificação próprios dos mercados de investimento imobiliário e turístico, e ponto de encontro da agenda cultural Lisboeta. Tem recuperado a sua vitalidade e identidade urbana, enfraquecida nos anos 1950, quando foram realizadas as intervenções de higienização e demolição da Baixa da Mouraria e a modernização da estrutura viária. A destruição do Mercado da Figueira e dos quarterões históricos da rua comercial da Mouraria e os adjacentes à área da Igreja de N. Sra. do Socorro e o seu Largo, provocou a deslocação de parte dos moradores para a periferia da cidade. As demolições deixaram o vazio urbano da Praça do Martim Moniz, que ficou expectante durante décadas. A Baixa da Mouraria, que tinha sido um centro nevrálgico do bairro, passou a ser uma zona esquecida e periférica do bairro até a inauguração, em 1997, da requalificação urbana e paisagística da nova Praça do Martim Moniz. Apesar de ser objeto de severas críticas transformou-se, com o decorrer do tempo, num autêntico espaço de convívio multicultural e multiétnico e espaço simbólico da diversidade (Menezes, 2012).

A situação de ruína do património edificado da Mouraria e a falta de sucesso dos Planos de Reabilitação Urbana dos anos 1980 e 1990 prolongou durante mais de meio século o seu abandono, processo que foi acompanhado pela tendência das gerações mais jovens em sair do bairro e pelo aumento dos fenómenos de pobreza e exclusão social (PA; 2009). O impulso revitalizador de políticas de requalificação urbana desde o ano 2009, como o Programa de Ação da Mouraria (PA, 2009) aprovado pelo QREN (Quadro de Referência Estratégico Nacional) e implementado no período 2011-13, o Plano de Desenvolvimento Comunitário da Mouraria (PDCM, 2012) e os programas BIP/ZIP desde 2011 até a 
atualidade, permitiram um conjunto de operações de valorização do património material e imaterial e da diversidade económica, social e cultural do bairro (Figura 2).

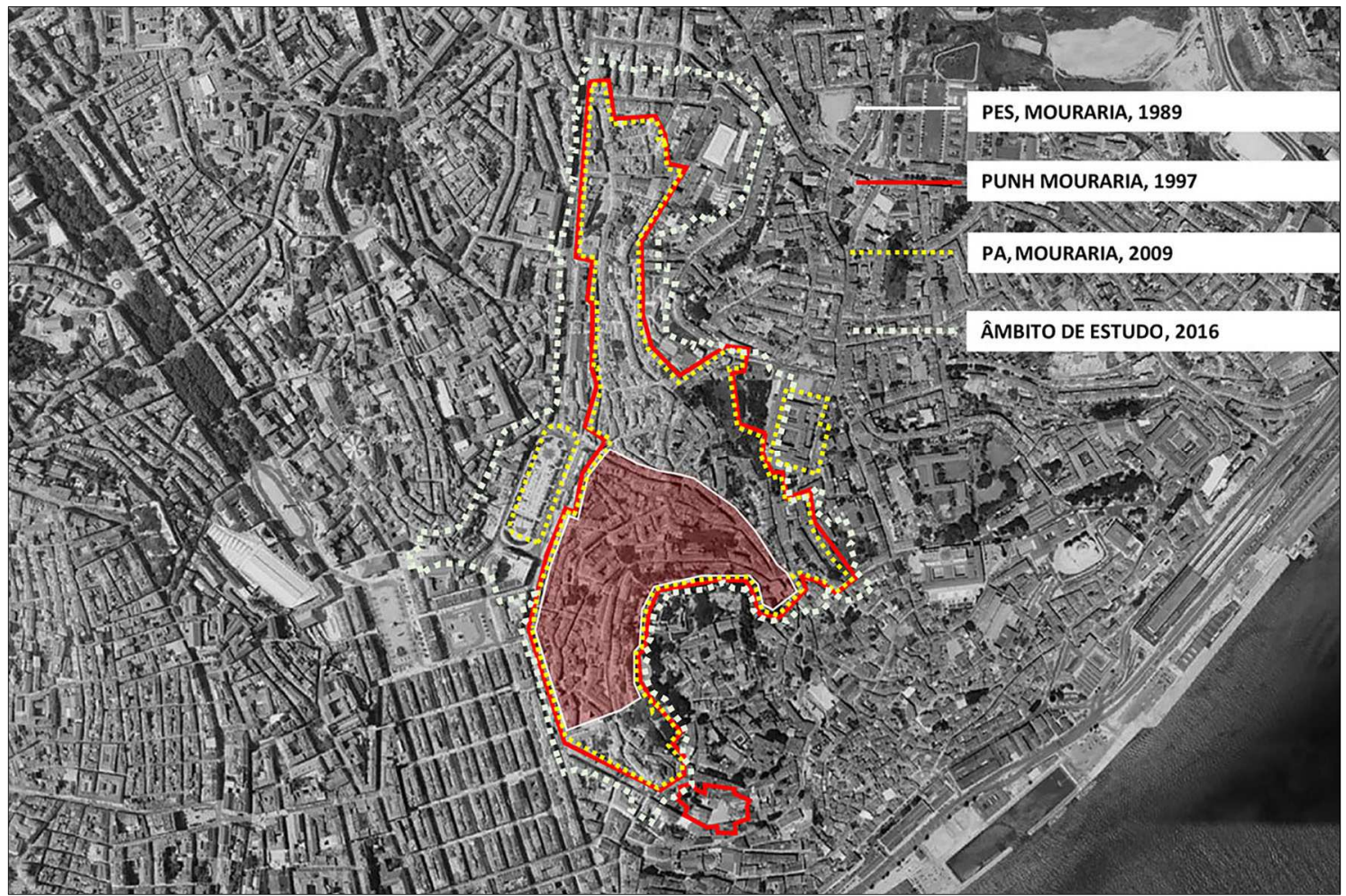

Figura 2 - Estratégias urbanas de reabilitação para a Mouraria (PES, 1989; PUNHM, 1997; PA, 2009) Diferentes limites de atuação. Limite em pontos branco, âmbito da presente pesquisa.

Fonte: Ana Moya

As melhorias físicas no bairro foram evidentes a partir da finalização das obras destinadas ao aumento da qualidade do sistema de espaços públicos, equipamentos e reabilitação de edifícios da autarquia. Destacam-se como intervenções relevantes a requalificação dos espaços públicos do Largo do Intendente ao Largo Adelino Amaro da Costa; na criação de um Percurso Turístico Cultural; na criação do Centro de Inovação da Mouraria; na criação do Sítio do Fado na casa da Severa e requalificação do Largo da Severa; e na reabilitação do Largo da Rosa. A intervenção institucional e promoção de um conjunto de operações estratégicas de valorização do espaço público, do património construído e sociocultural, foi também acompanhada do apoio económico continuado até à atualidade a dezenas de associações sociais e culturais locais que mantêm o seu papel ativo em projetos para diminuir os fenómenos de pobreza, exclusão social, e em promover a comunicação e a interação sociocultural no bairro, as tradições populares e o convívio multiétnico. 
A multiculturalidade na Mouraria faz parte da identidade e da história do bairro e não é um fenómeno social recente. Este é um dos valores intrínsecos e imateriais mais relevantes da sua paisagem urbana. A Mouraria nasce multicultural no ano 1170, como espaço segregado e comunal de mouros e judeus fora das muralhas da cidade. Espaço de convívio multicultural e comercial com a comunidade cristã, especialmente nas áreas do novo arrabalde da Mouraria até 1496, com a expulsão das minorias religiosas do País. No período da Revolução Industrial a Mouraria destaca-se por uma imigração nacional proveniente na sua maioria de Coimbra, Braga e Viana do Castelo, e estrangeira, da Galícia (Espanha) (Plano Especial de Salvaguarda da Mouraria, 1989)². Acrescenta-se nos anos 1970 uma população imigrada dos países do PALOP (Países Africanos de Língua Oficial Portuguesa) e entre eles também uma população de origem Indo-Português, com Hindus e Muçulmanos, que revitalizam o comércio na sua maioria de revenda e a grosso (Malheiros, 1996; Mapril, 2010). Entre os anos 1990 até a atualidade chegam novos residentes provenientes na sua maioria da China, Bangladeche, Paquistão e Nepal, com uma repercussão na estrutura funcional do bairro e na vitalidade urbana de serviços e comércios multiétnicos, estabelecendo as suas próprias organizações sociais e associações religiosas (Igreja Cristã Evangelista Chinesa, Associação Cultural Islâmica em Portugal (ACIPT), a Mesquita Baitul Mukarram e o Templo Indiano da Comunidade Ravidassia). Todas estas novas associações multiétnicas contribuem para a reconfiguração da atual identidade urbana da Mouraria.

\section{Os processos de mudança social, cultural e económica}

A consequente colmatação do tecido urbano e o crescimento da densidade populacional de Lisboa no início do século XX fez desaparecer os espaços rurais, zonas verdes, jardins e hortas que existiram integrados no tecido construído e na envolvente do bairro, e que estavam ligados a uma identidade da paisagem urbana própria da Mouraria, suburbana, rural e sustentável baseada numa rede de hortas de consumo de proximidade. A rua da Mouraria seguia o vale do esteiro de São Jordão, um dos afluentes do Tejo, que ainda no

\footnotetext{
${ }^{2}$ Câmara Municipal de Lisboa- Planos Especiais de Salvaguarda Alfama e Mouraria: propostas para debate público. Lisboa: CML, 1989; Alfama e Mouraria, caracterização sociológica e do edificado: análise preliminar. Lisboa: CML, 1989.
} 
século XVI conservava-se alagadiço ${ }^{3}$. A abundante água permitia a proliferação da cultura intensiva de hortas chamadas almoinhas na Comuna Moura, e no século XIV destacavam as margens e lombas do vale como terras de semeadura, hortas e olivedos. No século. XVIII o vale, na artéria principal que saía da porta de São Vicente, ainda continha hortas e campos. Os terrenos de cultura extensiva de cereais, olivais e árvores frutais estavam ligados em particular aos conventos (Mosteiro da Rosa, Colégio de São Antão-o-Velho, Paróquia de N. Sra do Socorro, Convento de N. Sra do Desterro, ou de N. Sra de Graça), os quais detinham um quinto ou sexto de área urbana verde (Rodrigues, 1997: 48). No século XVIII eram conhecidos os passeios às hortas e falava-se nos escritos da época das meijoadas nas hortas da Mouraria como prática social (Dias, 1987:131). Uma prática que continuou nos boémios anos 1820, quando o Fado desce às hortas, e onde nas quintas, casinhas e "retiros" organizavam-se bailes, cantava-se Fado, jogava-se e comiam-se petiscos. O eixo do regueirão do esteiro de São Jordão, num suceder de terrenos agrícolas, veio a dar lugar em 1859 à rua Direita dos Anjos, seguida pela Nova rua da Palma em 1862, que ligava a estrada de Santa Barbara até Arroios. Mais tarde essa linha viária seria transformada na Avenida Av. Almirante Reis (Sá, 1992:61).

O processo de terciarização e zonificação comercial e de serviços consequência da mudança dos tempos, e da vontade de modernização e higienização do centro histórico de Lisboa nos anos 1950, fez desaparecer a identidade da paisagem urbana da Mouraria, como espaço urbano produtivo, com uma estrutura industrial, artesanal e de convívio de subsistência, operária e bairrista consolidada no século XIX. A industrialização intensificou-se em Lisboa e no bairro da Mouraria a partir de 1850, com a mecanização da indústria (De Sá, 1992:61). Neste período, no auge da Revolução Industrial, e até os anos de 1930, a Mouraria contabilizou 139 estabelecimentos industriais (PDM, 1938). Os estabelecimentos eram variados e dispersos pelo bairro, instalados em lojas e caves de prédios habitacionais, e associados à indústria metalo-mecânica, oficinas de serralharia, latoaria, ferreiros, torneiros, oficinas de tipografia, cartonagem, vestuário ou calçado e construção civil, tal como são contabilizados no relatório Elementos para o Estudo do Plano de Urbanização da Cidade de Lisboa (1938) de Emídio Abrantes. Nesta época, e para melhorar a falta de habitação

\footnotetext{
${ }^{3}$ João G. Faria da COSTA- Plano de Remodelação da Baixa (1956-58, p.66). [Consultado 05.2016]. Disponibilidade e acesso: http://arquivomunicipal2.cm-lisboa.pt.
} 
construíram-se habitações dentro de pátios de palácios e conventos, encostadas às paredes e muros (Pátio do Jordão, Pátio das Osgas, Pátio do Coleginho, Pátio do Marquês de Castelo Melhor, Pátio do Salvador, Pátio do Ceitil, Pátio Miguel Rodrigues). A densidade populacional era grande, atraindo ao bairro os jovens de províncias devido às oportunidades laborais e aos preços económicos dos alojamentos. Emídio Abrantes destacava, em 1930, uma densidade populacional diurna de $950 \mathrm{hab} / \mathrm{ha}$ (PDM, 1938). Para resolver o problema de espaço de habitação os industriais construíam "Vilas Operárias". As vilas mais conhecidas na Mouraria são a Vila Júlia, a Vila Almeida, a Vila Eduardo e a Vila Luz Pereira. Este período histórico transformou a paisagem urbana num espaço multifacetado e auto-suficiente, onde a população podia passar-se uma vida inteira sem ter necessidade de sair do bairro (Dias, 1987:27). A Mouraria também continha serviços à escala urbana com a multitude de tabernas e atividades lúdicas que se abriam à cultura boémia de Lisboa. O século XIX representa para a Mouraria uma mudança na abertura às atividades de lazer e espetáculo. Implantam-se atividades lúdicas de caráter popular (Jogo da Pela, Teatro Apolo, a Feira Popular, o antigo Coliseu).

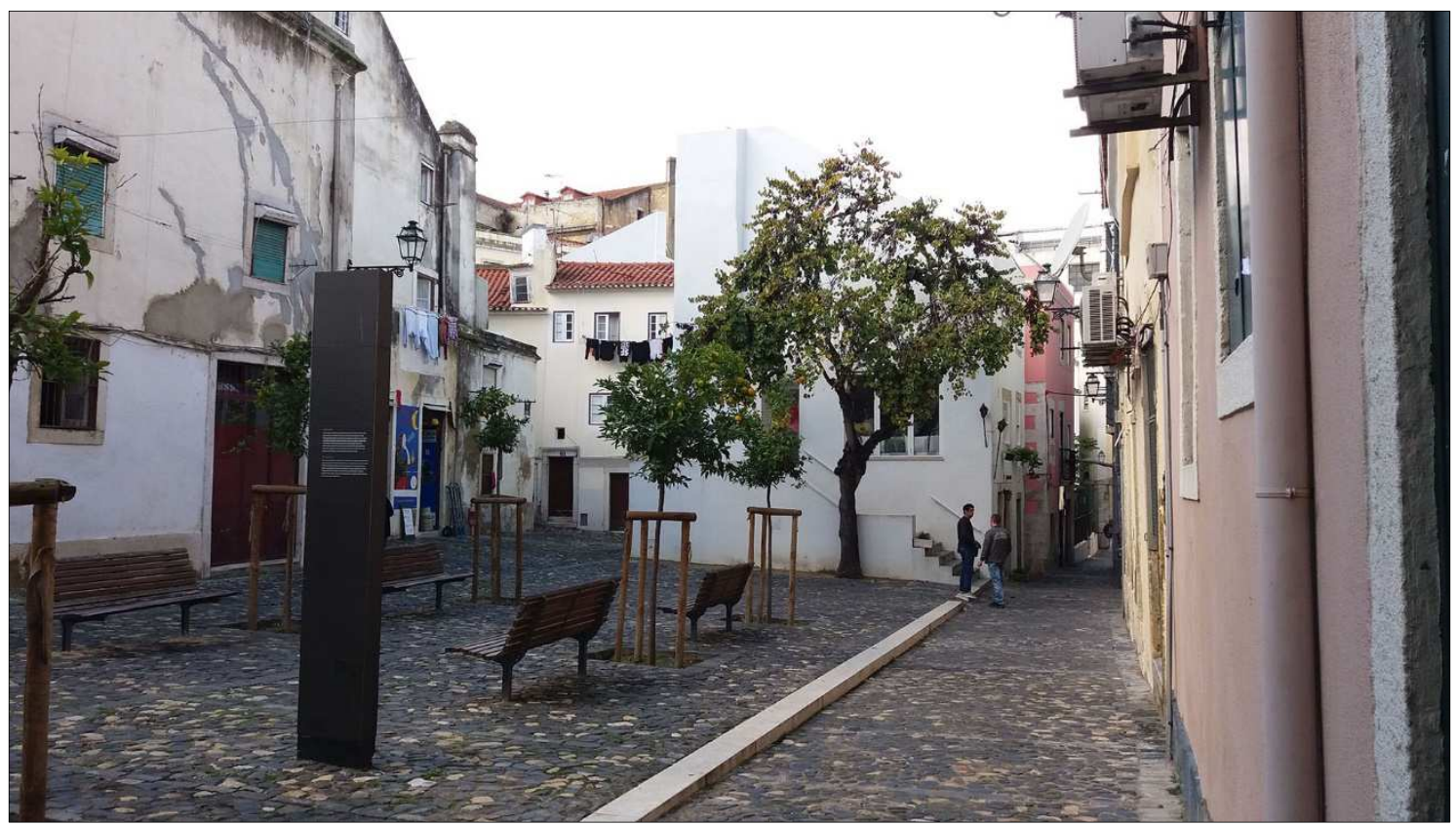

Figura 3 - Requalificação do espaço público do Largo da Severa, no Programa de Ação da Mouraria (2009) implementado no período 2011-13. Largo da Severa, 2016. Fonte: Ana Moya.

As tascas e botequins ligados ao aparecimento do Fado fazem perpetuar a identidade cultural da Mouraria até os nossos dias como berço do Fado, à volta do mito de Maria 
Severa (1820-46), fadista que viveu e morreu no bairro. Este valor patrimonial imaterial que chega até aos nossos dias fundamenta parte das intervenções estratégicas urbanas de 2009 à volta da Mouraria Fadista (Figura 3), esquecendo que o bairro também foi reconhecido, na época, como uma zona infecta e suja, de criminalidade, pobreza, prostituição e alcoolismo (Mendes, 1996). Com o progressivo desaparecimento da indústria em meados do século XX, das atividades artesanais e armazéns, também começa a diminuir a densidade populacional que faz enfraquecer uma cultura e identidade popular bairrista e o conceito do bairro como uma aldeia. A falta de intervenção no património edificado provocou a consequente degradação do tecido de habitação durante mais de meio século. Cabe destacar que em 1989, a indústria e os armazéns ainda somavam 45\% da sua estrutura funcional (Plano Especial de Salvaguarda da Mouraria,1989) ${ }^{4}$. No ano 2016, no estudo de caracterização do bairro realizado para a presente pesquisa, contabilizou-se unicamente um $1 \%$ da sua estrutura funcional (Moya, Batista, 2016).

\section{Super-diversidade do espaço urbano da Mouraria no século}

\section{XXI.}

Na segunda década do século XXI, os efeitos do neoliberalismo e a globalização são evidentes no incremento da mobilidade social, dos fluxos migratórios e o aumento do turismo de massas, num contexto de "super-diversidade" urbana dos residentes da Mouraria. Este facto tem efeitos irreversíveis numa nova transformação dos processos sociais, culturais e económicos no bairro, e na mudança da natureza e identidade da paisagem urbana na sua totalidade. Com esta velocidade de mudança tanto do tecido social e económico, como do edificado, a preservação da autenticidade da sua identidade urbana dependerá da qualidade das práticas e valores sociais e culturais que provam estar vivos e ser verdadeiros. Estas práticas e valores sociais, culturais, processos económicos e dimensões intangíveis do seu património imaterial devem incluir toda a sua diversidade e

\footnotetext{
${ }^{4}$ Câmara Municipal de Lisboa- Planos Especiais de Salvaguarda Alfama e Mouraria: propostas para debate público. Lisboa: CML, 1989; Alfama e Mouraria, as operações de reabilitação urbana: orientações estratégicas e principais medidas. Lisboa: CML,1989.
} 
identidade social (Turner, 2015). Esta autenticidade baseia-se no equilíbrio que se estabeleça entre a "super-diversidade" dos modelos de vida migratória e as suas práticas culturais (Vertovec, 2007), a continuidade das tradições bairristas e os novos padrões de consumo turístico.

No bairro da Mouraria destacava-se a existência de 51 nacionalidades diferentes no ano 2009, (Fonseca, McGarrigle, 2012), e no ano 2011 os estudos estatísticos revelavam que 8\% da população era imigrante, a sua maioria dos países do PALOP (41\%), Bangladesh, Paquistão e Nepal entre outros países Asiáticos (19\%), Europeus (17\%), Brasileiros (11\%)

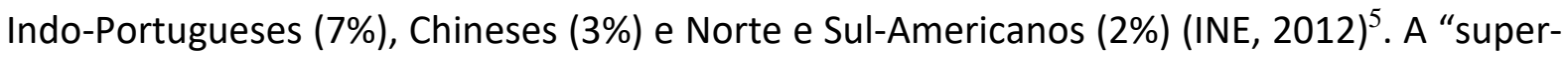
diversidade" implica uma amplitude dos canais e condições migratórias, de legalidade ou ilegalidade, de padrões de distribuição espacial, uma divergência nos mercados de trabalho, uma variabilidade nos perfis etários e nos limites de estadia (Vertovec, 2007:1025). A temporalidade residencial é uma variável que afetará as dinâmicas de integração e interação cultural no bairro.

Nesta amálgama diversificada de indivíduos em movimento dentro do bairro da Mouraria, a experiência individual e pessoal sempre está marcada pela instabilidade e pela fragilidade do seu mundo subjetivo (Baumann, 2000). Uma situação onde os vínculos emocionais com o lugar são temporários provoca um comportamento de carência de esforço e o perigo do desinteresse e falta de afeto pelo ambiente envolvente, podendo-se gerar padrões de deslocação, isolamento e sentido de não pertença ao lugar, com consequências negativas para a continuidade e construção identitária da paisagem. A natureza do espaço urbano da Mouraria é dinâmica e viva, e as semânticas contidas nos seus espaços urbanos abrangem a variabilidade e justaposição dos discursos dos diferentes grupos geracionais e multi-étnicos ali existentes (Figura 4).

\footnotetext{
5 INE. Instituto Nacional de Estatística. Censos 2011, Resultados definitivos. Região Lisboa, 2012.
} 

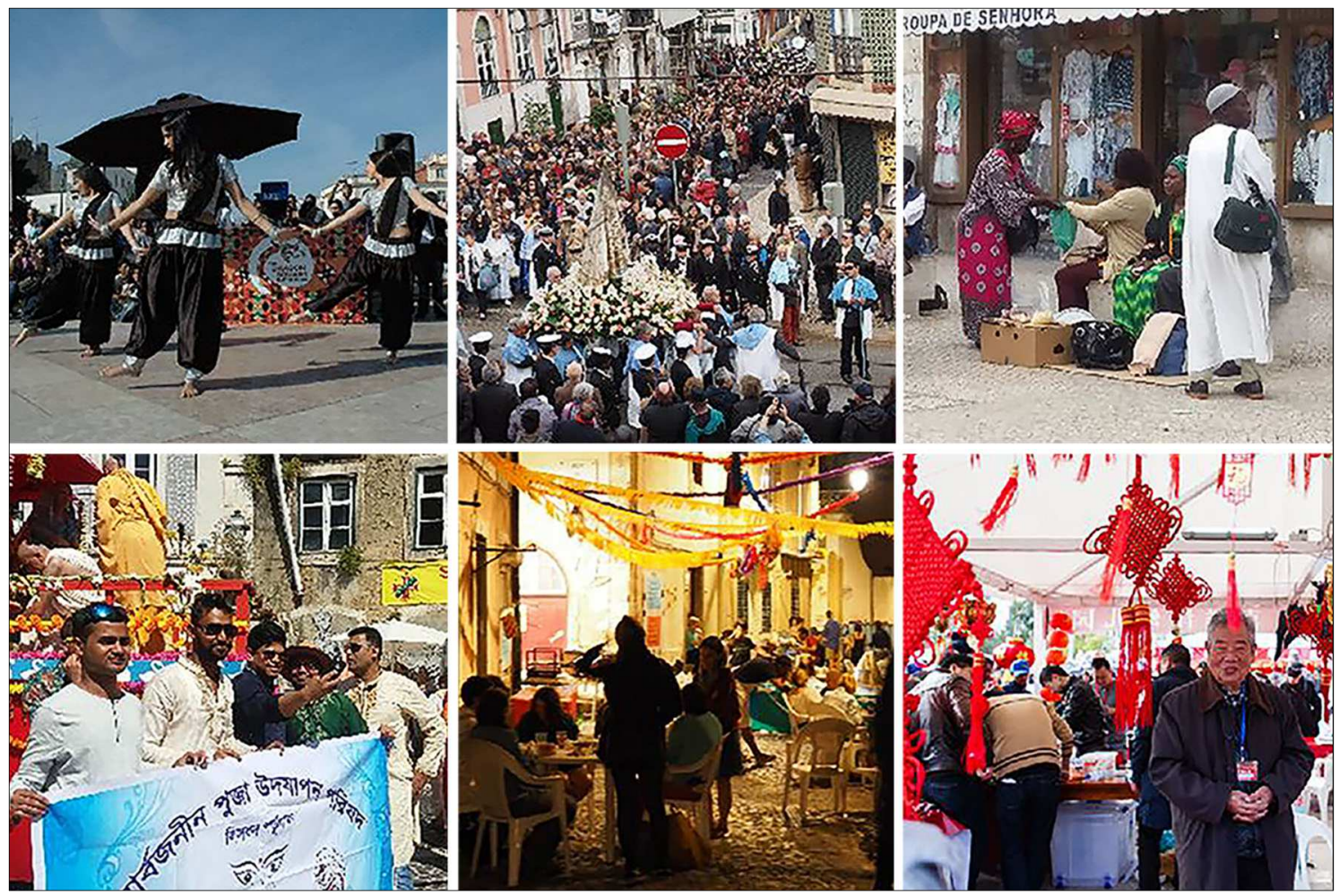

Figura 4 - 0 carácter multicultural do bairro da Mouraria e a presença de grupos multiétnicos no calendário de festividades e atividades de lazer do bairro.

Fonte: Carla Rosado, Mercado Fusão e Ana Moya

A identidade patrimonial da sua paisagem não se pode resumir a uma única maneira de perceber, conceber ou vivenciar o espaço. Existe uma multiplicidade de discursos que constantemente estão a ser construídos e que estão a enriquecer a memória do lugar. A diversidade cultural intensifica a interação com o mesmo grupo étnico, mas a Mouraria tem visto aumentar as interações entre grupos (Menezes, 2004; Fonseca, 2009). A construção da identidade do bairro da Mouraria requer a capacidade e a sensibilidade dos seus residentes para se identificarem e reapropriarem emocionalmente de um espaço urbano em constante transformação, desconhecido e estranho tanto para os de "dentro" como para os de "fora" (Menezes, 2004), e do seu conhecimento e interpretação das continuidades e legados históricos. As descontinuidades discursivas entre os diferentes grupos geracionais fazem necessária a transmissão contínua de conhecimento e de adaptação dos novos e antigos padrões de experiência (Manheim, 1923). 


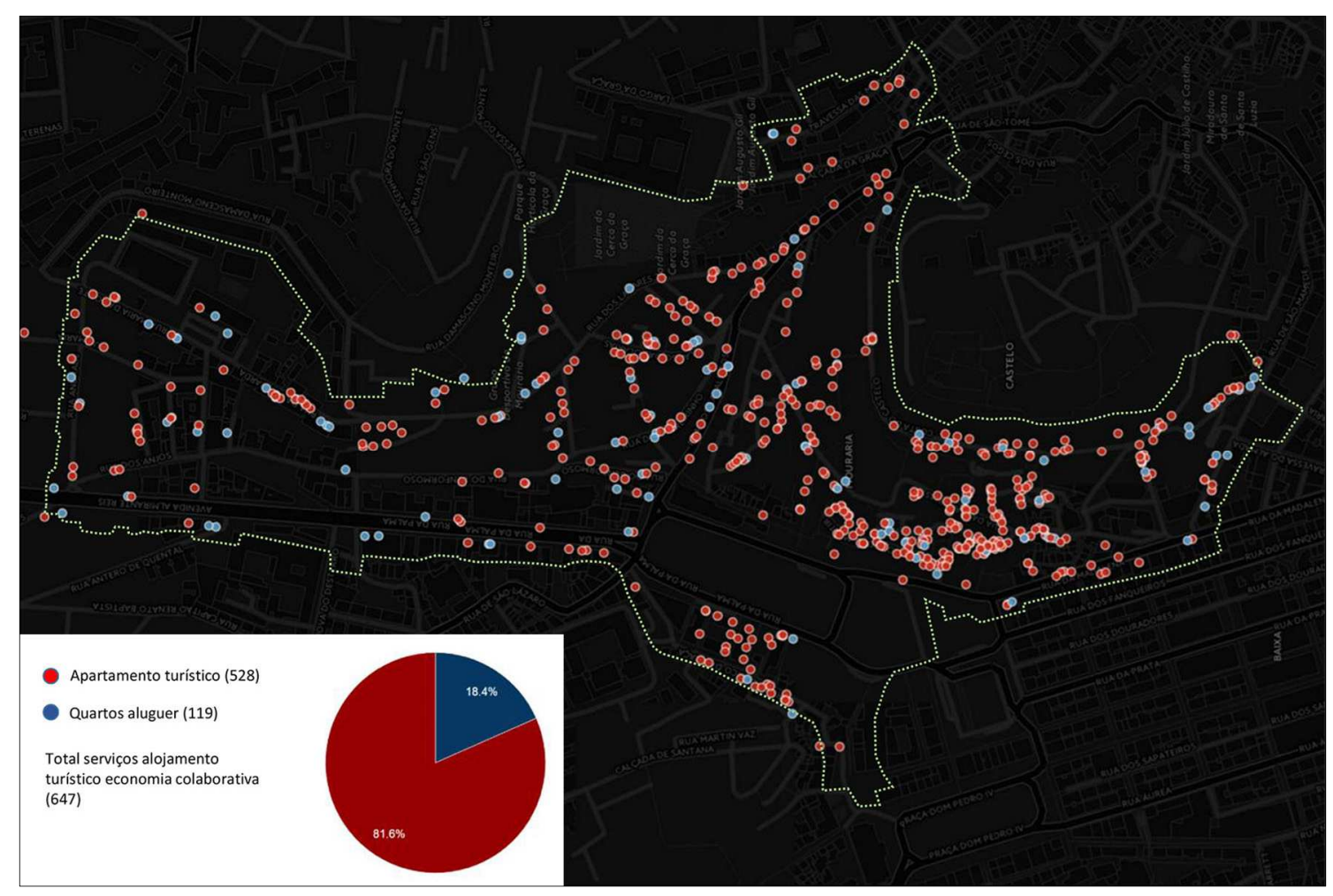

Figura 5 - Oferta de serviços de alojamento da plataforma virtual Airbnb. Classificação de apartamentos turísticos e quartos de aluguer. Mouraria, Maio 2016. Fonte: Ana Moya

O aumento do turismo de massas e o dinamismo no consumo cultural e de cidades das novas gerações digitais, está a desequilibrar a relação entre o número de residentes e visitantes no bairro da Mouraria. A sociedade digital tem revolucionado as práticas e o consumo de lazer. Existe por parte dos turistas um desejo por experimentar o espaço urbano com todos os sentidos, com o envolvimento da experiência corporal nas interações sociais no espaço (Urry, 2007). Este facto tem levado ao aumento da demanda de alojamento turístico nas residências dos moradores do bairro, dentro do consumo colaborativo e das plataformas digitais como o Airbnb e o turismo criativo e de experiência (Figura 5). No ano 2016, no estudo de caracterização do bairro realizado para a presente pesquisa, contabilizou-se na estrutura funcional do bairro um número de serviços maior (68\%), comparativamente ao comércio (31\%). Os serviços estão direcionados à Hotelaria (67\%) e dentro dela ao sector turístico e de lazer. O Alojamento turístico (Hotéis, Residenciais, Alojamento Local e Albergues de Juventude) tem uma presença física em termos oficiais de $16 \%$ dos serviços. No entanto, se incrementarmos a oferta de serviços de alojamento da plataforma virtual Airbnb, atinge-se um valor de 62\%. Este novo turismo 
procura flexibilidade na oferta turística, qualidade e autenticidade e experiências imersivas e íntimas, tornando mais instáveis os padrões de fidelidade aos lugares turísticos, pondo em causa esta autenticidade cultural e vivencial. A pressão do investimento privado para a preservação do património construído da Mouraria pode levar, com o tempo, à musealização do bairro como espaço para o desenvolvimento de serviços de hotelaria, alojamentos turísticos e os investimentos de capital estrangeiro. A cultura urbana e a paisagem urbana vendem, e o património cultural das comunidades é um valioso produto de mercado na indústria turística. Esta é uma realidade que não se pode evitar e que o próprio turismo incentiva. Este facto nos faz reflexionar sobre como o património cultural, visto como incentivo para dinamizar o consumo turístico e os processos de desenvolvimento económico, pode entrar em conflito com a própria expulsão dos seus residentes locais, atuais responsáveis de que o património imaterial seja autêntico.

\section{Padrões de sustentabilidade e o papel das associações locais}

A identidade do bairro da Mouraria está ligada aos processos psicológicos de apego, familiaridade e identidade do lugar. O sentido de pertença é necessário para o bem-estar psicológico e este depende de que não ocorra o desarraigamento, ou aflição emocional (Fullilove, 1996). A "perda do lugar" e o sentimento de não pertença dos filhos do bairro, significa a alienação e a completa desorientação, porque perdem-se as crenças e ações ligadas a uma continuidade da história vital do "eu" no lugar. O sentido de identidade espacial do "eu" no lugar é fundamental para a própria sanidade mental e a maior ameaça para o bem-estar emocional é a desintegração da comunidade. No ano 2004, no marco de uma investigação de doutoramento em antropologia sobre a identificação e análise das imagens identitárias da Mouraria, realizou-se um estudo à população mais envelhecida do bairro. Este estudo apresenta uma clara evidência da "perda do lugar" dos "filhos da Mouraria", acompanhada de tristeza e nostalgia por um bairro que se encontra em processo de transformação (Menezes, 2004: 205-06). A sua perceção da mudança, de não continuidade com o passado, cede à presença de "outra Mouraria" com novas práticas sociais e culturais, não identificadas com aquilo que era típico de um bairro popular. No ano 
2004, esta perceção de mudança está acentuada pela transformação da própria comunidade que no passado convivia quase como numa aldeia. Os entrevistados falam da falta de solidariedade e convivência entre vizinhos e na diminuição no empenho dos membros da comunidade por manter os rituais e tradições comemorativas do bairro (o Fado, as marchas populares, os arraiais, a procissão, a vida da rua), e culpabilizava-se a chegada de pessoas "estranhas" ao bairro. Comprovava-se no estudo que as segundas e terceiras gerações dos nascidos no bairro, e das famílias constituídas nos anos 1940, 50 e 60, viviam fora do bairro, verificando-se a falta de continuidade geracional das tradições identitárias. No período entre 1981 e 2011 a população da Mouraria diminuiu de 12.279 para 5.824 residentes. No entanto, entre 2001 e 2011 cresceu um 3\%. Os residentes não nascidos em Portugal ascendem a $8 \%$ da população, tendo o bairro $24 \%$ dos residentes maiores de 65 anos (PDCM, 2012). As unidades familiares com um único membro ascendem a 44\%, valor que está diretamente relacionado com o envelhecimento da população e a morte de um membro do casal ou associado às exigências da vida da população ativa. A soma de famílias de um só membro ou de dois membros atinge 74\% (PDCM, 2012). Estes dados apresentados são significativos para entender como os novos padrões de vida familiar, o aumento da demanda turística, e a chegada de novos residentes imigrados vai repercutir nas dinâmicas urbanas de convívio e participação na comunidade. Neste sentido a identidade da paisagem urbana da Mouraria, entendida como construção do sentido do "eu" no lugar, não pode ser durável porque os critérios subjetivos e os padrões culturais são móveis como também os processos de mudança do ambiente urbano. A mudança da identidade do espaço urbano também afeta o apego e o desprendimento dos indivíduos que habitam esses espaços, reformulando constantemente suas subjetividades (Seller \& Urry, 2006).

O sentimento de não pertença e a nostalgia de um passado cultural e de um espaço urbano desaparecido deteriora a capacidade de construção de uma identidade do lugar no presente. A apropriação do lugar depende das emoções e comportamentos que modulam o contacto com o espaço urbano, fonte do sentimento de proteção e satisfação de uma comunidade (Fullilove, 1996). Iniciativas culturais e sociais geradas por novos membros da comunidade, nos últimos anos, têm permitido fortalecer a colaboração e a construção de uma identidade "super-diversa" dentro da Mouraria. O objetivo tem sido reforçar e 
restabelecer os laços de familiaridade com o lugar, reparar o sentido de pertença e construir novas identidades espaciais e patrimoniais dentro da diversidade e multiculturalidade. Às festividades históricas do bairro da Mouraria e da cidade de Lisboa, como a Procissão de Nossa Senhora da Saúde em Abril-Maio ou as festas dos Santos Populares durante o mês de Junho, somam-se durante a última década no Largo do Martim Moniz: as Festividades de comemoração do Ano Novo Chinês, que mobilizam a comunidade Chinesa em Lisboa; o Eidul-Fitr ou Festa do Fim do Ramadão, organizada pela Comunidade Islâmica de Lisboa (CIL) que mobiliza uma comunidade muçulmana transnacional; ou a Festividade do Bollywood Holli, que reúne a comunidade Hindu e muitos outros participantes de diversidade cultural, numa festa indiana de cor, dança e música durante o mês de Abril. Estas novas festividades constroem novos vínculos e identidades no lugar (Figura 4).

Depois de levado a cabo o Programa de Ação (2011-2013), o Plano de Desenvolvimento Comunitário da Mouraria $(2012)^{6}$ e os programas BIP/ZIP desde 2010, podemos observar o reforço das organizações sociais no bairro (Figura 6). Junto com as associações históricas no bairro como o Grupo Desportivo da Mouraria (1936), o Centro Escolar Republicano Almirante Reis (1911), o Chapitô (1986), e as Associações Regionais (Gouveia, Minho, Covilhã, Lafões), que têm tido um papel fulcral na preservação das tradições populares e identitárias do bairro, somam-se nos últimos anos a fundação de associações pela iniciativa de novos grupos jovens e ativos, com a vontade de dinamizar e ampliar o panorama cultural da comunidade local. Destaca-se o papel da Casa Independente (2012), Sou, Movimento e Arte (2004) com o seu projeto Largo Residências (2011), Associação Renovar a Mouraria (2008) e Cozinha Popular da Mouraria (2012). Estas novas Associações reúnem tanto os próprios moradores do bairro como pessoas que vivem fora dele, implicadas todas elas no desenvolvimento, apoio e construção de dinâmicas sociais e interculturais na Mouraria. Destacam-se outros coletivos artísticos que têm dinamizado o bairro através da experimentação artística como o Centro em Movimento (1998), com um trabalho contínuo de interação com o bairro e as pessoas que nele habitam através da investigação e estudo do corpo e do movimento. O Ebano Collective (2012), coletivo que trabalha a arte, a etnografia e a intervenção no espaço público. Também é relevante, o trabalho individual de

\footnotetext{
${ }^{6}$ Câmara Municipal de Lisboa - Programa de Desenvolvimento Comunitário da Mouraria. Lisboa: CML, 2012. [Consultado 12.2016]. Disponibilidade e acesso: http://www.aimouraria.cm-lisboa.pt/pdcm.html.
} 
artistas comprometidos na colaboração com a comunidade e com a construção de um novo património cultural. Destacam-se ainda artistas femininas, como as fotógrafas Camila Watson, Carla Rosado e a investigadora na dança, pedagoga e coreografa Madalena Vitorino, que têm contribuído com um trabalho artístico de contato direto com a população, a estabelecer uma visão crítica e ativa das identidades particulares e individuais da Mouraria (Figura 7).

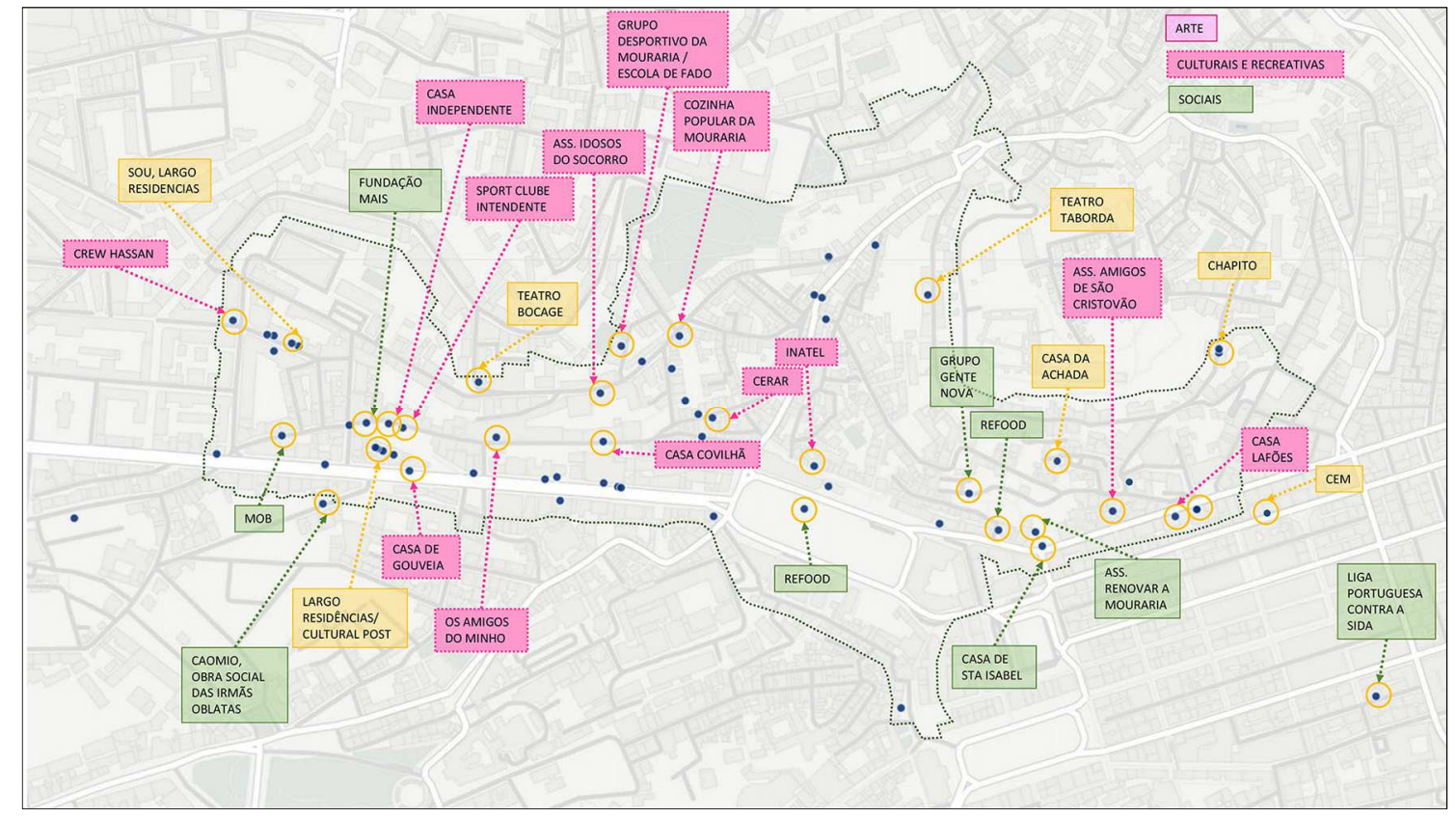

Figura 6 - Principais associações culturais e recreativas, sociais e de intervenção artística no bairro. Mouraria, Maio 2016. Fonte: Ana Moya

Durante as diferentes edições do programa BIP/ZIP, desde 2010, foram financiados na Mouraria uma trintena de projetos de parcerias locais, sendo relevantes em 2011 o apoio às associações locais Associação Renovar a Mouraria, Cozinha Popular da Mouraria, Largo Residências, e a Casa da Achada; no ano 2012 o apoio à Associação da Casa Independente; no 2013 o apoio à Associação SOU Largo, Associação Chapitô e Artéria; e nos anos consecutivos até a atualidade tem servido para consolidar as agendas, os projetos e programas sociais, culturais e artísticos das Associações já presentes no bairro. 


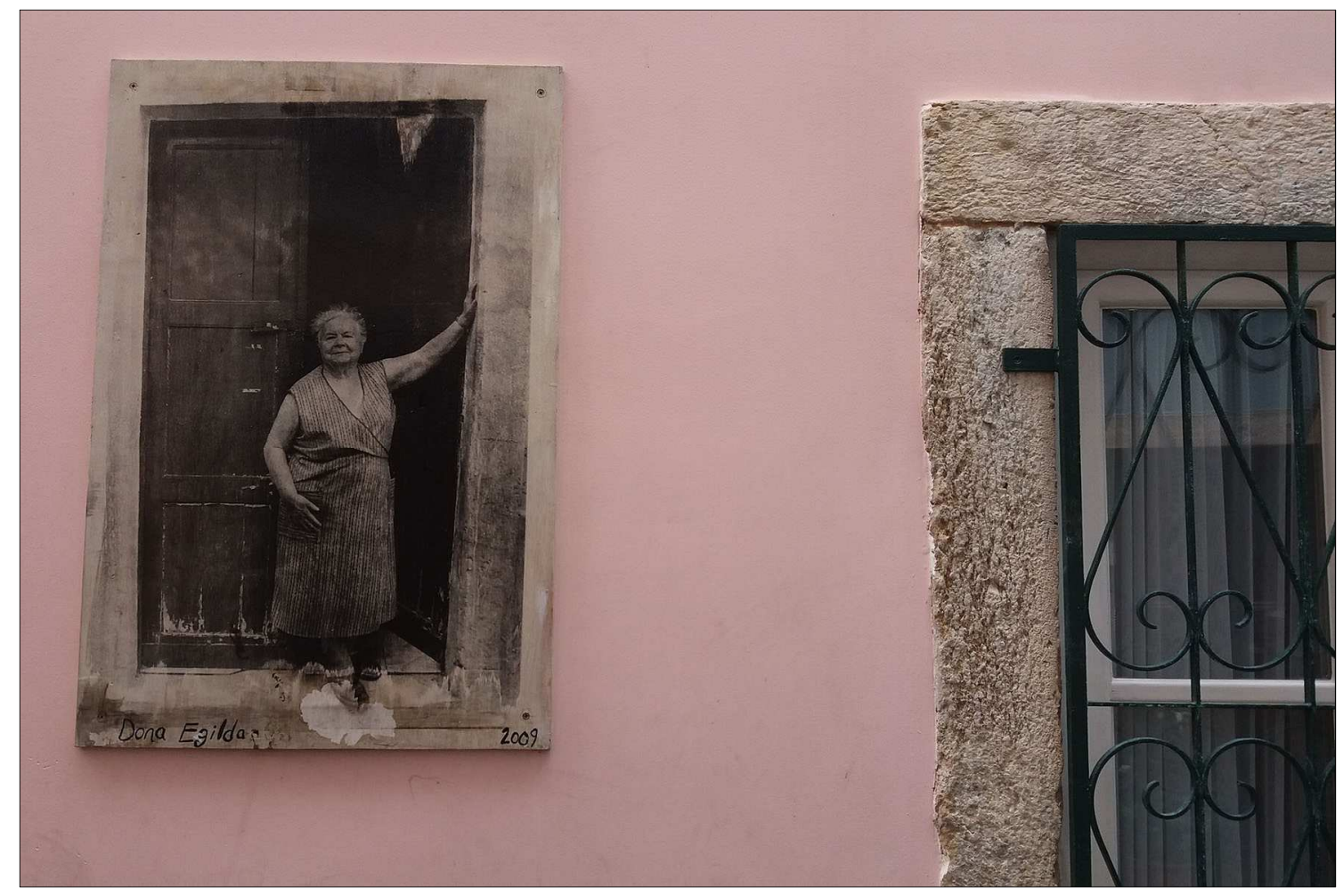

Figura 7 - Trabalho de fotografia socio documental (2009). Exposição permanente ao ar livre da fotógrafa Camila Watson. Beco das Farinhas Mouraria, Novembro 2015. Fonte: Ana Moya

\section{Conclusão}

A sustentabilidade sociocultural do bairro da Mouraria envolve o respeito pelas tradições históricas e os novos valores identitários das suas comunidades, com a participação ativa de todos os seus residentes, dentro da inclusão, a diversidade cultural e geracional. Esta sustentabilidade fundamenta-se na continuidade dos legados históricos, mas também na criatividade, o cooperativismo e a construção de relações socioculturais no "agora" que permitem a coesão social e a redefinição de novos universos mentais e emocionais ligados ao lugar. A estrutura associativa do bairro tem um papel fulcral, tanto no que toca a associações regionais e históricas, aquelas dos coletivos imigrados, como a jovens associações dinamizadoras. As últimas constroem novos imaginários que abrangem a inclusão de novas vozes semânticas e culturais. Frente à fragilidade e mudança do espaço físico e das comunidades, a continuidade do património imaterial da Mouraria encontra-se na própria continuidade destas estruturas associativas, que apesar da mobilidade dos seus 
próprios membros, criam identidades e pontos de resistência frente aos mercados globais e a pressão imobiliária. No entanto, a existência destas estruturas associativas dentro da Mouraria também é frágil, frente ao perigo da perda da sua localização física dentro do bairro quando são expostas à mesma pressão imobiliária que o resto dos membros da comunidade.

\section{Referências bibliográficas}

BAUMAN, Zygmunt. Modernidade Líquida (2000). P. Dentzien (Trad.). Rio de Janeiro: J. Zahar Editor, 2001. ISBN 978-85-7110-598-0

DIAS, Tavares Marina. Lisboa Desaparecida (Vol. I). Primeira Edição. Lisboa: Quimera Editores, 1987. ISBN 9789725890479

FONSECA, Maria Lucinda. Imigração, Diversidade e Novas Paisagens Étnicas e Culturais. In LAGES, Mário Ferreira e MATOS, Artur Teodoro (Eds.), Portugal: Percursos de Interculturalidade, Volume II- Contextos e Dinâmicas. Lisboa: Alto Comissariado para a Imigração e Minorias Étnicas (ACIME), 2009, p. 49-96. ISBN 978989-8000-58-3

FONSECA, Maria Lucinda e MCGARRIGLE, Jennifer (Coords.) Modes of Inter-ethnic Coexistence in Three Neighbourhoods. Lisbon Metropolitan Area: a Comparative Perspective. Lisboa: Edições Colibri, Centro de Estudos Geográficos, 2012. ISBN 978-989-689-177-0

FULLILOVE, Mindy. Psychiatric Implications of Displacement: Contributions from the Psychology of Place. The American Journal of Psychiatry, Dec. 1996, 153: 12, p. 1516-1523. DOI: 10.1176/ajp.153.12.1516

ICOMOS. Guidance of Heritage Impact Assessments for Cultural World Heritage Properties. Paris: International Council on Monuments and Sites, 2011. [Consultado 12.2016]. Disponibilidade: http://whc.unesco.org/document/139487.

JIGYASU, Rohit. Reducing Disaster Risks to Urban Cultural Heritage: Global Challenges and Opportunities. Journal of Heritage Management, Vol 1, Issue 1, 2016, pp. 59-67. DOI: 10.1177/2455929616649476

MALHEIROS, Jorge M. Imigrantes na Região de Lisboa: Os Anos da Mudança. Lisboa: Edições Colibri, 1996. ISBN 972-8288-35-2

MANNHEIM, Karl. The Problem of Generations (1923). In KECSKEMETI, Paul (Ed.), Essays on the Sociology of Knowledge / by Karl Mannheim (1952). London: Routledge, 1997, p. 276-322. ISBN 0415150833

MAPRIL, José. Banglapara: Imigração, Negócios e (In)formalidades em Lisboa. Etnográfica, Vol 14 (2), 2010, p. 243-263. DOI: 10.4000/etnográfica.284

MENDES, Vera. Socorro, Freguesia Mourisca: Berço do Fado. Lisboa: Câmara Municipal de Lisboa, 1996.

MENEZES, Marluci. Debatendo Mitos, Representações e Convívios acerca da Invenção de um Bairro Lisboeta. Sociologia. Revista da Faculdade de Letras da Universidade do Porto, Vol.1, Número Temático: Sociologia Imigração, Diversidade e Convivência Cultural., 2012 p. 69-95. ISSN 0872-3419

MENEZES, Marluci. Mouraria, Retalhos de um Imaginário. Significados Urbanos de um Bairro de Lisboa. Oeiras: Celta Editora, 2004. ISBN 972-774-207-6

MOYA, Ana e BATISTA, Desidério. A Dimensão do Património Intangível em Paisagens Urbanas Históricas Multiculturais. Bairro da Mouraria como Estudo de Caso. Portugal, Território de Territórios, Atas do IX 
Congresso Português de Sociologia, Lisboa: Associação Portuguesa de Sociologia, 2017. ISBN 978-989-97981-37.

RODRIGUES, Teresa Ferreira. Cinco Séculos de Quotidiano. A Vida em Lisboa do Século XVI aos Nossos Dias. Lisboa: Edições Cosmos, 1997. ISBN 972-762-060-4

SÁ, Vítor de. Lisboa no Liberalismo (Lisboa 1805-1851). Lisboa: Livros Horizonte, 1992. ISBN 972-24-0838-0

SELLER, Mimi e URRY, John. The New Mobilities Paradigm. Environment and Planning A38 (2), 2006, pp. 207226. DOI 10.1068/a37268

TURNER, Michael. Social Sustainability of the Historical Urban Landscape. In ALBERT, Marie-Theres. (Ed.), Perceptions of Sustainability in Heritage Studies. Heritage Studies 4. Berlin: de Gruyter, 2015, p.99-112. ISBN 978-3-11-041527-8

UNESCO. Recomendação sobre a Paisagem Histórica Urbana. In Anexo Resolução 36C/15, Vol.1. Paris, 2011. Organização das Nações Unidas para a Educação, as Ciências e a Cultura. [Consultado 12.2016]. Disponibilidade: http://portal.unesco.org/en/ev

URRY, John. Mobilities. Camdridge: Polity Press, 2007. ISBN 978-07456-3418-0

VERTOVEC, Steven. Super-diversity and its Implications. Ethnic and Racial Studies. London: Routledge, 2007, p. 1024-1054. DOI 10.1080/01419870701599465 